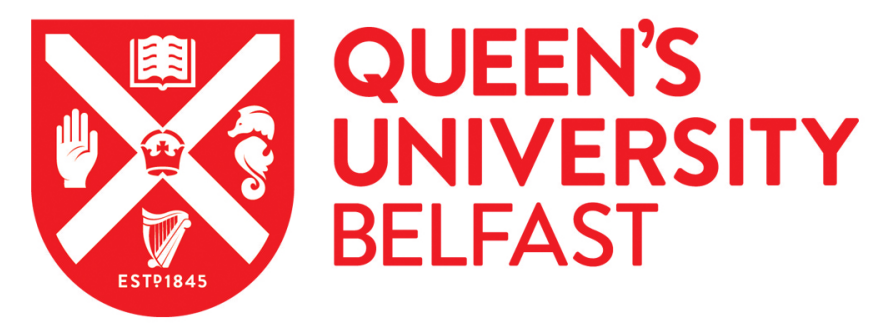

\title{
Increasing intention to cook from basic ingredients: A randomised controlled study
}

Lavelle, F., Hollywood, L., Caraher, M., McGowan, L., Spence, M., Surgenor, D., McCloat, A., Mooney, E., Raats, M., \& Dean, M. (2017). Increasing intention to cook from basic ingredients: A randomised controlled study. Appetite, 116, 502-510.

\section{Published in:}

Appetite

\section{Document Version:}

Peer reviewed version

Queen's University Belfast - Research Portal:

Link to publication record in Queen's University Belfast Research Portal

Publisher rights

(c) 2017 Elsevier Ltd. All rights reserved. This manuscript version is made available under the CC-BY-NC-ND 4.0 license

http://creativecommons.org/licenses/by-nc-nd/4.0/,which permits distribution and reproduction for noncommercial purposes, provided the author and source are cited.

\section{General rights}

Copyright for the publications made accessible via the Queen's University Belfast Research Portal is retained by the author(s) and / or other copyright owners and it is a condition of accessing these publications that users recognise and abide by the legal requirements associated with these rights.

Take down policy

The Research Portal is Queen's institutional repository that provides access to Queen's research output. Every effort has been made to ensure that content in the Research Portal does not infringe any person's rights, or applicable UK laws. If you discover content in the Research Portal that you believe breaches copyright or violates any law, please contact openaccess@qub.ac.uk. 


\section{Accepted Manuscript}

\section{M}

Appetite

Increasing intention to cook from basic ingredients: A randomised controlled study

Fiona Lavelle, Lynsey Hollywood, Martin Caraher, Laura McGowan, Michelle Spence, Dawn Surgenor, Amanda McCloat, Elaine Mooney, Monique Raats, Moira Dean, Professor

PII: S0195-6663(16)30887-X

DOI: 10.1016/j.appet.2017.05.024

Reference: $\quad$ APPET 3475

To appear in: Appetite

Received Date: 2 December 2016

Revised Date: 17 April 2017

Accepted Date: 13 May 2017

Please cite this article as: Lavelle F., Hollywood L., Caraher M., McGowan L., Spence M., Surgenor D., McCloat A., Mooney E., Raats M. \& Dean M., Increasing intention to cook from basic ingredients: A randomised controlled study, Appetite (2017), doi: 10.1016/j.appet.2017.05.024.

This is a PDF file of an unedited manuscript that has been accepted for publication. As a service to our customers we are providing this early version of the manuscript. The manuscript will undergo copyediting, typesetting, and review of the resulting proof before it is published in its final form. Please note that during the production process errors may be discovered which could affect the content, and all legal disclaimers that apply to the journal pertain. 


\section{ACCEPTED MANUSCRIPT}

Title: Increasing intention to cook from basic ingredients: A randomised controlled study

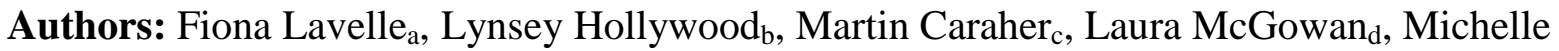
Spence $_{\mathrm{a}}$, Dawn Surgenor $\mathrm{b}$, Amanda McCloat , Elaine Mooney $_{\mathrm{e}}$, Monique Raats $_{\mathrm{f}}$, Moira Dean a Institute for Global Food Security, School of Biological Sciences, Queen's University Belfast, $U K$

${ }_{b}$ Department of Hospitality and Tourism Management, Ulster Business School, Ulster University, $U K$

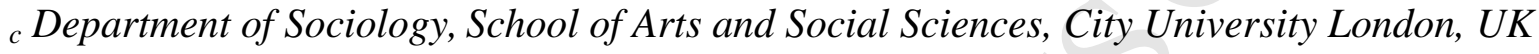
${ }_{d}$ Centre for Public Health, School of Medicine, Dentistry and Biomedical Sciences, Queen's University Belfast, $U K$

e Department of Home Economics, St Angela's College, Sligo, Ireland ${ }_{f}$ Food, Consumer Behaviour and Health Research Centre, School of Psychology, University of Surrey, UK

Names for PubMed indexing: Lavelle, Hollywood, Caraher, McGowan, Spence, Surgenor, McCloat, Mooney, Raats, Dean.

\section{Email addresses:}

FL: flavelle01@qub.ac.uk

LH: 1.hollywood@ulster.ac.uk

MC: M.caraher@city.ac.uk

LM: Laura.McGowan@qub.ac.uk 
MS: m.s.spence@qub.ac.uk

DS: e10218120@uucde.ulst.ac.uk

AM: amccloat@stangelas.nuigalway.ie

EM: emooney@stangelas.nuigalway.ie

MR: M.Raats@surrey.ac.uk

MD: moira.dean@qub.ac.uk

Running Head: Increasing intention to cook from basic ingredients.

\section{Corresponding author:}

Prof Moira Dean

Professor

Institute for Global Food Security

School of Biological Sciences

Queen's University Belfast

University Road

Belfast, BT7 1NN, UK.

Email: moira.dean@qub.ac.uk Tel: +44 (0) 28 90976561, Fax: +44 (0) 2890976513 


\section{Abstract}

2 The promotion of home cooking is a strategy used to improve diet quality and health. However,

3 modern home cooking typically includes the use of processed food which can lead to negative

4 outcomes including weight gain. In addition, interventions to improve cooking skills do not always

5 explain how theory informed their design and implementation. The Behaviour Change Technique

6 (BCT) taxonomy successfully employed in other areas has identified essential elements for

7 interventions. This study investigated the effectiveness of different instructional modes for learning to

8 cook a meal, designed using an accumulating number of BCTs, on participant's perceived difficulty,

9 enjoyment, confidence and intention to cook from basic ingredients.

141 mothers aged between 20-39 years from the island of Ireland were randomised to one of four conditions based on BCTs (1) recipe card only [control condition]; (2) recipe card plus video modelling; (3) recipe card plus video prompting; (4) recipe card plus video elements. Participants rated their enjoyment, perceived difficulty, confidence and intention to cook again pre, mid and post experiment. Repeated one-way factorial ANOVAs, correlations and a hierarchical regression model were conducted.

Despite no significant differences between the different conditions, there was a significant increase in enjoyment $(\mathrm{P}<0.001)$, confidence $(\mathrm{P}<0.001)$ and intention to cook from basics again $(\mathrm{P}<0.001)$ and a decrease in perceived difficulty $(\mathrm{P}=0.001)$ after the experiment in all conditions. Intention to cook from basics pre-experiment, and confidence and enjoyment (both pre and post experiment) significantly contributed to the final regression model explaining $42 \%$ of the variance in intention to cook from basics again.

Cooking interventions should focus on practical cooking and increasing participants' enjoyment and confidence during cooking to increase intention to cook from basic ingredients at home. 
25 Keywords: Cooking, Experiment, Randomised Controlled Study, Confidence, Enjoyment, Perceived

Difficulty, Basic Ingredients, Ireland ${ }^{1}$

\section{Introduction}

29

Recent concerns regarding the increase in diet related chronic diseases and obesity [1-3] have been partially attributed to a decrease in diet quality $[4,5]$. Factors associated with the decline in diet quality include; snacking, increased consumption of takeaways and meals consumed outside the home environment as well as the increased consumption of convenience products, many of which contain excessive energy, sugars, fats and salt and low concentrations of dietary fibre [6-9]. These factors have also transformed the domestic meal preparation landscape where meals are prepared at home. Current trends show that less time is being spent in meal preparation, larger portions are being served, less skills are being used to prepare meals and convenience products are being used in the majority of meals, if not the entirety of each meal [10-13].

In response to this transformation in food preparation and the types of food products typically consumed, there has been an increase in the number of nutrition intervention programmes; specifically cooking skills interventions $[14,15]$. The desire for the population to return to home meal preparation has been highlighted throughout government policies and the academic literature, and by the media and health professionals [16-19]. While research has shown positive outcomes resulting from home meal preparation including improved diet quality and weight reduction $[9,15,20,21]$, it has also been shown that the inclusion of processed convenience products in modern home meal preparation $[10,13]$ has negative dietary implications [8]. Therefore, when discussing the merits of

\section{${ }^{1}$ Abbreviations:}

SCT: Social Cognitive Theory; BCT: Behavioural Change Technique; ROI: Republic of Ireland; NI: Northern Ireland; UK: United Kingdom; RCT: Randomised Controlled Trial. 
home meal preparation in the public domain, the possible negative side effects of consuming processed convenience foods (typically those high in sugars, salt, fat and additives), including weight gain [21] and a possible link to an increased risk of autoimmune diseases must be highlighted [22].

Thus, what may be needed is the encouragement to increase cooking from minimally processed basic ingredients and a reduction in the use of convenience products [23], similar to the guidelines of other countries, such as in Brazil, where one of the key recommendations is "Always prefer natural or minimally processed foods and freshly made dishes and meals to ultra-processed products" [24].

In general, the aim of the majority of cooking interventions has been to improve diet quality through increasing cooking and food skills [15] and not solely on cooking from basic ingredients. However, studies have shown that consumers with higher levels of cooking skills are less likely to use many convenience products [25]. Self-efficacy theory [26] has shown that perceived confidence and difficulty may play key roles in the implementation of a behaviour. In addition, intrinsic motivation (the enjoyment in performing the activity), is theorised to be a driver in behavioural change in Selfdetermination theory [27]. The importance of enjoyment in sustained behavioural change has also been qualitatively supported by those who were successful in their behaviour change maintenance [28]. Furthermore, some studies have shown that increased enjoyment in cooking may follow the learning of simple and easily replicable recipes which increase confidence and help participants to engage more with cooking in their home environment, with a positive impact on diet quality $[14,17$, 25,29,30]. In addition, Chapman-Novakofski and Karduck [31] found a significant decrease in the perceived difficulty in meal preparation by women who participated in a cooking intervention study. Enjoyment, confidence and perceived difficulty have been theoretically linked to behaviour change and empirically connected to home cooking in general, however little is known about their impact on cooking from scratch. As there is an increased awareness of negative effects of the use of convenience products in modern home cooking, it is important to understand how enjoyment, confidence and perceived difficulty are associated with cooking from basic ingredients.

Despite the current interest in cooking skills interventions, many of the devised adult programmes tend not to be underpinned by a theoretical framework [15]. Those that use theories cite psychological 
theories, such as Social Cognitive Theory (SCT) [32] but provide few details on how these were operationalised or implemented for the intervention. Additional theories used in interventions and teaching cooking skills includes Applied Behavioural Analysis, Systematic Instruction and Information Processing Theory and Blooms Taxonomy [33-37].

77

While there is overlap between these theories from different disciplines, for example relating to key techniques such as observation and modelling, the important techniques that provide optimal learning of cooking skills remain unclear. Using an existing framework that can be applied to multiple types of interventions with the goal of changing or increasing certain behaviours would be one method which would enable the identification and replication of successful elements and allow comparisons between interventions. Michie and colleagues [38] developed such a framework, a 40-item CALO-RE taxonomy of Behaviour Change Techniques (BCTs) such as goal setting and provision of information. This taxonomy was created so that researchers could identify and repeat successful elements in interventions that target change in behaviours. The identification of common successful BCTs in different types of interventions is important as there is an increasing number of general health interventions incorporating cooking demonstrations and practical sessions as one element of the intervention.

This study had two aims; firstly, to examine the role of enjoyment in cooking, perceived confidence to cook a recipe, and perceived difficulty of meal preparation on the intention to cook from basic ingredients. The second aim was to investigate the effectiveness of different ecologically valid instructional modes for learning to cook a meal based on accumulating numbers of behaviour change techniques on perceived difficulty, enjoyment in cooking, confidence in cooking and intention to cook from basic ingredients.

\section{Methods}

\section{Sampling and Design}


This research was a dual-site randomised controlled study conducted in Sligo (Republic of Ireland [ROI]) and Coleraine (Northern Ireland [NI], United Kingdom [UK]). A dual-site study was chosen as the project was funded as an island of Ireland study and therefore a sample from both NI and ROI was required. Using G Power, a sample size of 148 participants was calculated as being required for a medium effect size. In total, 160 young mothers that lived within a 30-mile radius of the two sites were recruited by the market research company SMR. Mothers were chosen as the target population as they remain the primary source for learning cooking skills [39] and recent research suggests that there is a culinary transition and that mothers may not have the skill level to prepare meals from scratch [40].

Participants were eligible if they were between the ages of 20 to 39 years, had young children, were of a lower socioeconomic status, had no strict dietary requirements (such as lactose intolerant, vegetarian) and prepared meals more than twice a week using mainly pre-prepared ingredients. The participants' incentive package for taking part in the study included a small financial gift as contribution for time and travel, a cookbook and a cooked meal to take home. A final sample of 141 participants was obtained (77 participants in NI, 64 participants in ROI) due to 18 participants failing to show for their allocated times and 1 mother being unable to participate due to health and safety concerns regarding willingness to participate with a child in a baby sling. Although the sample consists of two different jurisdictions, from previous research of island of Ireland samples [41] a difference was not expected across the two locations of the one sample. Table 1 highlights that there is no difference across the locations in this study, with the exception of age where there is a marginally significant difference between jurisdictions. As the difference in age is only two years between the groups and no important differences in cooking behaviours would be expected for such a small difference, the results were aggregated and treated as one island of Ireland sample.

\section{Table 1: Basic Demographic characteristics of participants by jurisdiction}

\begin{tabular}{|l|l|l|l|}
\hline Baseline & NI (77) & ROI (64) & Significance $(p)$ \\
\hline & M (SD) & M (SD) & \\
\hline Age & $29.57(5.36)$ & $31.50(5.96)$ & 0.05 \\
\hline
\end{tabular}




\begin{tabular}{|l|l|l|l|}
\hline Cooking Skills Confidence & $63.96(15.09)$ & $67.89(13.94)$ & 0.12 \\
\hline Food Skills Confidence & $82.23(20.70)$ & $86.49(19.97)$ & 0.22 \\
\hline Likelihood to cook again & $4.70(1.76)$ & $4.98(1.71)$ & 0.34 \\
\hline
\end{tabular}

Cooking skills confidence range: 30-97; Food skills confidence range: 14-124.

123 Using Michie and colleagues [38] BCT taxonomy, commonly used BCTs in cooking interventions were identified. These BCTs were then applied to different instruction modes as part of the design of our experimental study, to cook a lasagne dish from basic ingredients. For example, BCT 21, to provide information on how to perform the behaviour, was used as the control instruction mode. Participants in this group were given a recipe of a lasagne dish. In the other conditions an additional commonly used BCT was incorporated as explained below.

Participants were randomly assigned within site to one of four conditions (1) recipe card only [control condition]; (2) recipe card plus video modelling; (3) recipe card plus video prompting; (4) recipe card plus video elements. The four conditions were based on BCTs commonly found in cooking and food skills interventions which had ecological validity. Ecological validity is the degree to which the measures, methods and setting of the study must reflect and be relevant and applicable to the real world setting. In this study each condition had to be similar to a real-life method of learning how to cook. The accumulative effect of the BCTs [38], within which the mode of instruction varied (see Table 2), on the intention to cook the meal again from basic ingredients was investigated. Each condition offered an instruction mode that could be used by a person when learning to cook. Participants were provided with instructions on how to cook a lasagne from basic ingredients based on one of four conditions within which the mode of instruction varied (Please see Table 2). All other aspects of the experiment (e.g. ingredients, equipment, allotted time and protocols, etc.) were identical in all four conditions and across both sites including the observers (two researchers attended all sessions across both locations to maintain consistency). 


\begin{tabular}{|c|c|c|c|c|}
\hline & Condition 1 & Condition 2 & Condition 3 & Condition 4 \\
\hline Experimental Instructions & $\begin{array}{l}\text { Recipe plus picture only - } \\
\text { static cookbook condition - } \\
\text { CONTROL }\end{array}$ & $\begin{array}{l}\text { Video modelling (plus } \\
\text { recipe) } \\
\text { (watch full demo as a group, } \\
\text { then -> cook - with recipe + } \\
\text { photo) }\end{array}$ & $\begin{array}{l}\text { Video prompting (plus } \\
\text { recipe) } \\
\text { (do it in a sequence, step by } \\
\text { step - > cook - with recipe + } \\
\text { photo) }\end{array}$ & $\begin{array}{l}\text { Video 'elements' (plus } \\
\text { recipe) - user has total } \\
\text { control over what to } \\
\text { watch/re-watch) -> cook - } \\
\text { with recipe + photo }\end{array}$ \\
\hline Ecological Validity & $\begin{array}{l}\text { Similar to traditional } \\
\text { cookbook }\end{array}$ & Similar to seeing on TV & $\begin{array}{l}\text { Similar to school - teacher } \\
\text { demonstrates skills and } \\
\text { students repeat }\end{array}$ & $\begin{array}{l}\text { Similar to watching video } \\
\text { clips online, can watch parts } \\
\text { of videos, rewind, fast } \\
\text { forward, repeat. }\end{array}$ \\
\hline \multirow[t]{4}{*}{ BCT Explanations } & $\begin{array}{l}\text { 21) Provide instruction on } \\
\text { how to perform behaviour }\end{array}$ & $\begin{array}{l}\text { 21) Provide instruction on } \\
\text { how to perform behaviour }\end{array}$ & $\begin{array}{l}\text { 21) Provide instruction on } \\
\text { how to perform behaviour }\end{array}$ & $\begin{array}{l}\text { 21) Provide instruction on } \\
\text { how to perform behaviour }\end{array}$ \\
\hline & & $\begin{array}{l}\text { 22) Model or demonstrate } \\
\text { the behaviour }\end{array}$ & $\begin{array}{l}\text { 22) Model or demonstrate } \\
\text { the behaviour }\end{array}$ & $\begin{array}{l}\text { 22) Model or demonstrate } \\
\text { the behaviour }\end{array}$ \\
\hline & & & 9) Set graded tasks & 9) Set graded tasks \\
\hline & & & & $\begin{array}{l}\text { 26) Behavioural } \\
\text { practice/rehearsal- As } \\
\text { regardless of whether the } \\
\text { participants watch the } \\
\text { podcasts or not, they are } \\
\text { being advised to 'practice' }\end{array}$ \\
\hline
\end{tabular}


Ethical approval for this study was obtained from Queen's University Belfast Research Ethics

Committee, Ulster University's Ethics Committee and St. Angela's College Sligo's Research and

147 Ethics Committee. All research was conducted in accordance with the guidelines given in the

148 Declaration of Helsinki. Participants provided consent and were aware of their right to withdraw.

\section{Procedure and Measures}

For the cooking experiment, participants were required to follow the instructions in their assigned condition to make a lasagne from basic or raw ingredients within 90 minutes. The lasagne recipe was taken from the funding body's cookbook and subsequently adapted and developed by the researchers to include multiple skills and different ingredients. Two of the authors (AMC and EM, lecturers in Home Economics) assessed multiple dishes from the cookbook and concluded that lasagne contained a wide and varied range of cooking skills with differing difficulty levels and also a substantial number of ingredients. It is a commonly made meal in the home (a nationally representative IOI survey was conducted $[39,42]$, from this it was shown that amongst young mothers lasagne was a common main meal) that can be supplemented with convenience products or replaced in its entirety by a ready-made version of the dish. Reed et al. [43] in an IOI population showed that lasagne was the most frequently purchased and favourite ready-made product as it was perceived to be very time consuming to prepare from basic ingredients in the home. Piloting of the cooking task included a green side salad to highlight how lasagne could be included as a component in a healthy meal, however, due to timing the salad was removed and the focus was on the preparation and cooking of the more complex lasagne.

The ingredients of the lasagne included low fat ingredients where possible to highlight that a dish that may not necessarily be considered healthy can be made healthier and depending on the side dishes and the frequency it is served, can be included in a healthy diet. In addition, this helped to show that common main meals that may not be seen as healthy, do not need to be excluded from the diet but can be adapted and depending on preparation can be included as part of a balanced diet. The ingredients and preparation instructions received by participants in the study can be seen in the supplementary material. While the focus of the current study was on cooking skills, cooking lasagne also includes 
171 wider food related skills such as planning, budgeting and affordability of cooking with basic

172 ingredients, storage, the transferability of the skills to other dishes, and substitution of ingredients for

173 adaption to family preferences, dietary requirements or to make the dish healthier. These wider food

174 related skills were elicited and discussed with participants as part of post-experimental focus groups,

175 but are not the focus of the current study. All aspects of this intervention were extensively piloted

176 from initial concepts to final format. Piloting was conducted at both sites to reduce any differences

177 between sites. Minimal changes occurred after these trials, such as the inclusion of background music

178 to make the atmosphere more relaxing and to give a 'homely feel' (participants in the pilot stated that

179 they would listen to the radio while cooking and never cook at home in silence), and the reduction of

180 the number of observers so as to reduce the stress on the participants. It was deemed acceptable for

181 observers to intervene in the experiment if it was felt there was a significant health and safety risk to

182 the participant, however, this occurred only three times, for meat handling and potential fire hazards.

183 All participants completed the cooking task at their own individual kitchen station fitted with all

184 equipment necessary to complete the dish, including individual hob and ovens. This was kept

185 consistent across both sites with the placing of all necessary equipment for the completion of the dish

186 on the unit benches and the removal from sight of any extra utensils that were not necessary for

187 completion of the dish. The setup of the individual kitchen units was inspected between each session

188 by the two researchers (FL, DS) that were present at all 16 sessions across both locations. There was a minimum of one spare kitchen unit for each session of the cooking task to ensure each participant would be able to complete the task even if there was a fault with equipment. Participants were not allowed to communicate or observe other participants during the cooking task. All measures were answered individually by participants without consultation.

193 All eligible participants completed an adapted cooking and food skills questionnaire at home [42]

194 prior to the experiment. This enabled the researchers to calculate baseline cooking skills confidence and food skills confidence. When all questionnaires were collected from participants, participants were informed of the dish they would be making. Next, participants answered questions relating to previous attempts at making lasagne and the types of ingredients used. Following this, participants 
were assigned to an individual kitchen unit and instructed to familiarise themselves with the unit (and tablets in conditions two to four). Participants in conditions two to four received a demonstration on how to use their individual tablets and headsets, which enabled them to watch the different videos depending on their condition. After the demonstrations, all participants were asked four questions which were repeated again at the mid-point (45 minute) and post-experiment (upon completion of the cooking task each participant individually answered this question and reported their end point to counteract any communication and bias; Mean $74.20 \mathrm{~min}$, SD 22.12). The four questions were; (1) at this moment how confident do you feel about producing a safe, edible meal (not at all confident to extremely confident); (2) At this moment, how enjoyable do you think you will find cooking this meal (not at all enjoyable to extremely enjoyable); (3) At this moment, how difficult do you think it will be to cook this meal (not at all difficult to extremely difficult); and (4) At this moment, do you think you would cook this meal from basic ingredients at home (not at all likely to extremely likely)? All answers were given on a 7 point Likert score, ranging from 1 to 7 .

\section{Data Analysis}

All data were analysed using IBM SPSS Statistics Version 22 (IBM Corporation, 2013). Descriptive statistics (means, standard deviations [SD]), Chi squared and ANOVAS with Tukey HSD post hoc tests were used to assess any baseline differences between the four conditions (recipe only, recipe plus full demo, recipe plus video prompting, recipe plus video elements). The answers to the four questions regarding confidence, enjoyment, perceived difficulty and intention to cook from basic ingredients again, were analysed as scores (1 to 7). Low scores indicated low levels of confidence, enjoyment and intention to cook again. However, low scores in perceived difficulty were positive scores as the less the participants perceived the task as difficult the better. Missing data was handled using listwise deletion as the missing values were scattered randomly through the dataset. Repeated measures one-way factorial ANOVAs with Bonferroni post hoc tests were conducted to test between and within conditions, to determine an interaction effect of the intervention for confidence, enjoyability, perceived difficulty and likelihood to cook again. Using correlations, the strength of the relationships among the variables were evaluated. Further, using a hierarchical regression model, it 
225

226

227

228

229

230

231

232

233

was determined how much of the variance in the dependent variable (likelihood to cook the meal again from basic ingredients) was accounted for by the predictor variables (likelihood to cook again at the beginning ( 0 minute), and both pre ( 0 minute) and post (individual finish times) scores for confidence, enjoyability, and perceived difficulty). For regression analyses, multicollinearity was assessed using the variance inflation factor and by examining the tolerance statistic. These were below the suggested critical values of 10 for variance inflation factor [44] and above 0.2 for tolerance [45], indicating that the level of multicollinearity was acceptable. In addition, the autocorrelation between the measures of the predictor variables was assessed in the analysis with the Durbin-Watson test and found to be acceptable at a value of 2.08. A level of 0.05 was used as the significance value for interactions in the analysis.

\section{Results}

\section{Baseline}

The baseline demographic details between the different conditions are displayed in Table 3. There were no differences between the mean scores of all measures by condition. Further, there were no differences between the conditions for: the highest level of education achieved $\left(\chi^{2}(1,139)=13.15, p\right.$ $=0.36)$, number of children $\left(\chi^{2}(6,139)=10.05, p=0.12\right)$, and perceived weight status $\left(\chi^{2}(9,140)=\right.$ $6.49, p=0.69)$. The majority of participants $(88.7 \%)$ reported eating lasagne at home. Of the participants that reported the ingredients they had used in previous lasagnes, $72 \%$ had used convenience products. The ingredients used by those participants that reported eating lasagne at home included: a lasagne 'meal kit' (9.9\%), 2 premade sauces (29.8\%), 1 premade sauce (19.9\%), from scratch - excluding lasagne sheets (23.4\%), unclear/don't make it (5.7\%). There was no difference between the conditions and the type of ingredients used in previous versions of lasagne $\left(\chi^{2}(12,125)=\right.$ $12.18, p=0.43)$. 
Table 3 - Baseline demographic characteristics of participants by condition

\begin{tabular}{|c|c|c|c|c|c|}
\hline Baseline & Significance $(p)$ & Recipe Only & Recipe + Full Video & Recipe + Video Prompting & Recipe + Video Elements \\
\hline \multirow[t]{2}{*}{ Number } & & 34 & 33 & 35 & 39 \\
\hline & & $\mathrm{M}(\mathrm{SD})$ & $\mathrm{M}(\mathrm{SD})$ & $\mathrm{M}(\mathrm{SD})$ & $\mathrm{M}(\mathrm{SD})$ \\
\hline Age & 0.27 & $31.52(5.77)$ & $30.03(5.51)$ & $31.28(5.64)$ & $29.18(5.78)$ \\
\hline Perceived Enjoyment (Pre) & 0.42 & $4.94(1.37)$ & $5.27(1.26)$ & $4.91(1.48)$ & $4.72(1.49)$ \\
\hline Perceived Difficulty (Pre) & 0.19 & $3.35(1.35)$ & $3.88(1.36)$ & $3.80(1.23)$ & $3.33(1.42)$ \\
\hline $\begin{array}{l}\text { Likelihood to cook again } \\
\text { (Pre) }\end{array}$ & 0.40 & $4.59(1.76)$ & $4.67(1.43)$ & $5.23(1.65)$ & $4.85(2.01)$ \\
\hline Perceived Confidence (Pre) & 0.49 & $4.71(1.47)$ & $4.49(1.54)$ & $4.63(1.21)$ & $4.20(1.67)$ \\
\hline Cooking Skills Confidence & 0.62 & $65.56(15.77)$ & $66.81(15.31)$ & $68.00(12.53)$ & $63.92(15.03)$ \\
\hline Food Skills Confidence & 0.05 & $88.64(20.92)$ & $82.13(19.78)$ & $88.80(17.72)$ & $77.72(21.45)$ \\
\hline
\end{tabular}

Cooking skills confidence range: 30-97; Food skills confidence range: 14-124. 
251

\section{Temporal effects}

252 Factorial repeated measures ANOVAs were conducted to check for the effects of the experiment and

253 an interaction effect, conditions and time on confidence scores, enjoyment scores, perceived levels of

254

255

256

257

258

259

260

261

262

263

264

265

266 difficulty, and likelihood to cook the meal again from basic ingredients. For each score no significant difference was found between the conditions; confidence $(\mathrm{F}=1.18(3,137), p=0.32)$, enjoyment $(\mathrm{F}=$ $0.54(3,136), p=0.66)$, perceived difficulty $(\mathrm{F}=0.39(3,137), p=0.76)$, and intention to cook again from basic ingredients $(\mathrm{F}=2.28(3,137), p=0.32)$. However, for each of these scores, a significant effect of time was seen (Figure 1). Confidence significantly increased across all time points $(p<0.001)$, with a large effect size $($ Eta squared $=0.44)$. A positive effect of time was found for enjoyment scores across all time points $(p<0.001$, eta squared 0.17$)$. Again for perceived difficulty scores a medium significant effect of time was found $(p=0.001$, eta squared $=0.10)$. There was a significant decrease between the start and midpoint and the start and the endpoint for perceived difficulty scores $(p<0.05)$, however, no further decrease was seen between the mid-point and the endpoint. Finally, there was a significant effect of time $(p<0.001)$ for intention to cook the meal from scratch again, with intention to cook increasing over each time point $(p<0.05)$, with a large effect size $($ Eta squared $=0.32)$. 


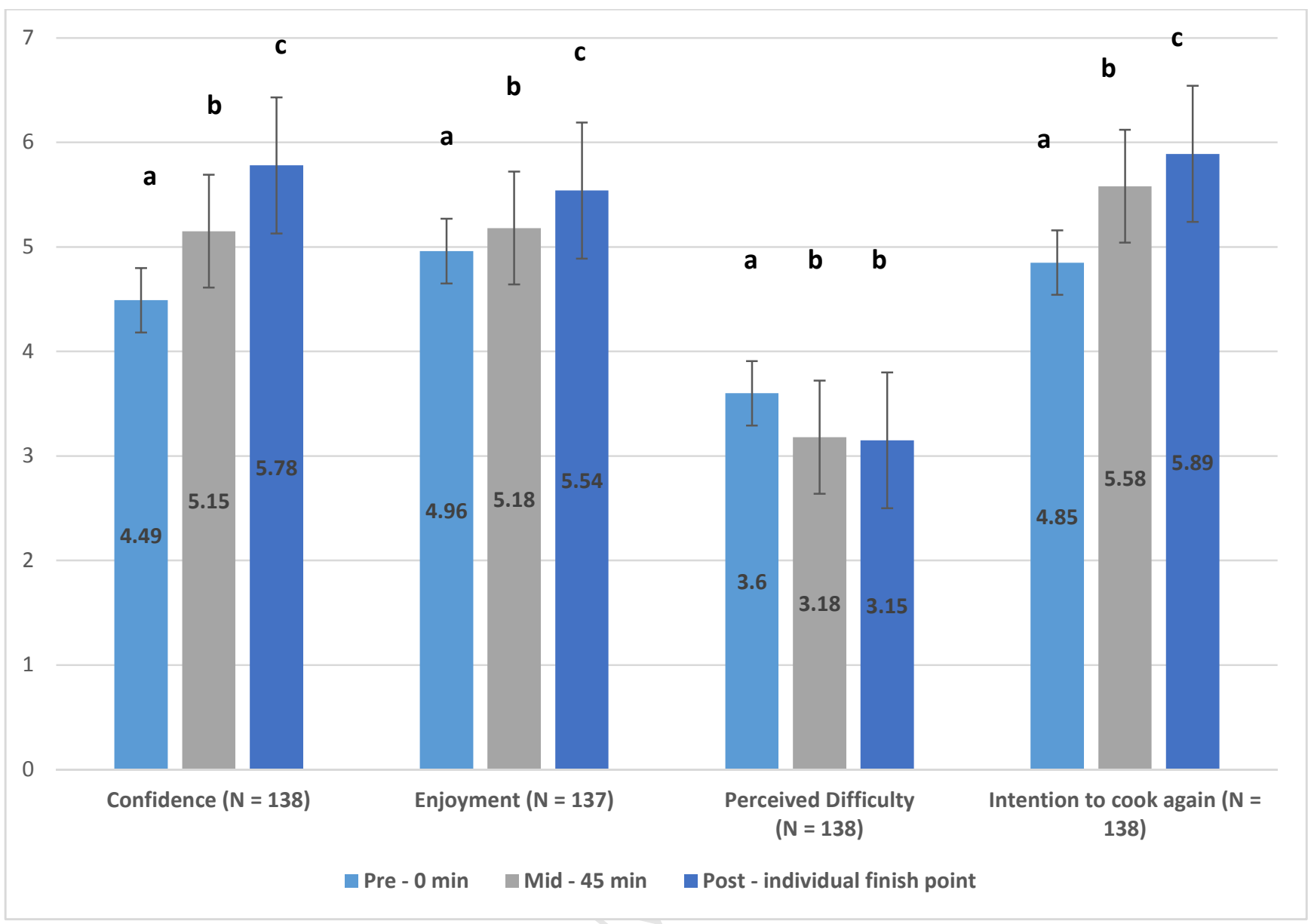

Figure 1: The effect of the overall experiment on confidence, enjoyment, perceived difficulty and intention to cook again. * Letters depict where significance lies between means; Error Bars represent Standard Error.

Predictors of Intention to cook from basic ingredients

. Confidence $(\mathrm{r}=0.38, p<0.01)$ and enjoyment $(\mathrm{r}=0.50, p<0.01)$ in the cooking experiment were positively associated with intention to cook from basic ingredients again. Perceived difficulty of cooking the lasagne was negatively correlated with intention to cook again $(r=-0.26, p<0.01)$. Similarly, confidence was positively correlated with enjoyment $(\mathrm{r}=0.42, p<0.01)$ and perceived difficulty was negatively correlated with both confidence $(\mathrm{r}=-0.27, p<0.01)$ and enjoyment $(\mathrm{r}=-$ $0.19, p<0.05)$

Table 4 shows the results of a hierarchical multiple regression analysis predicting intention to cook the meal from basic ingredients again. The baseline model included the participants' intention to cook 
281 the meal from scratch at the beginning of the experiment as a potential predictor of cooking from

282 scratch upon completion of the experiment. This variable accounted for $28 \%$ of the variance, with a

283 significant independent contribution $(p<0.001)$. As the different models are accumulative, models 1

284 and 2 control for initial conditions and model 3 tests the impact of enjoyment, perceived difficulty and

285 confidence on intention to cook from scratch. Model 2 included the participants' confidence,

286 enjoyment and perceived difficulty scores at the beginning of the experiment. These variables

287 accounted for a further $4 \%$ of the variance. In model 3, the model was adjusted to include

288 participants' confidence, enjoyment and perceived difficulty scores at the end of the experiment

289 which led to an additional 10\% of the variance being explained. Each model explained a significant

290 amount of variance $(p<0.05)$. The final model explained $42 \%$ of the total variance in participants'

291 intention to cook the meal from basic ingredients again. 
Table 4 - Hierarchical multiple regression across all conditions predicting intention to cook from scratch again

\begin{tabular}{|c|c|c|c|c|c|c|}
\hline \multirow[t]{2}{*}{ Variables } & \multicolumn{2}{|l|}{ Model 1} & \multicolumn{2}{|l|}{ Model 2} & \multicolumn{2}{|l|}{ Model 3} \\
\hline & B (SE) & $\boldsymbol{\beta}$ & B (SE) & $\boldsymbol{\beta}$ & B (SE) & $\boldsymbol{\beta}$ \\
\hline $\begin{array}{l}\text { Intention to cook from scratch again at start } \\
(\mathrm{N}=141)\end{array}$ & $.455(.062)$ & $.535^{* * *}$ & $.417(.074)$ & $.491 * * *$ & $.351(.072)$ & $.413 * * *$ \\
\hline Confidence at start $(\mathrm{N}=141)$ & & & $-.152(.092)$ & -.153 & $-.196(0.92)$ & $-.197 *$ \\
\hline Enjoyment at start $(\mathrm{N}=141)$ & & & $.287(.091)$ & $.272 * *$ & $.178(.090)$ & $.169 *$ \\
\hline Perceived Difficulty at start $(\mathrm{N}=141)$ & & & $-.007(.086)$ & -.007 & $-.035(.084)$ & -.032 \\
\hline Confidence at end $(\mathrm{N}=138)$ & & & $y$ & & $.263(.100)$ & $208 * *$ \\
\hline Enjoyment at end $(\mathrm{N}=137)$ & & & & & $.292(.102)$ & $.233 * *$ \\
\hline Perceived Difficulty at end $(\mathrm{N}=138)$ & & & & & $-.010(.074)$ & -.010 \\
\hline$\overline{\mathbf{F}}$ & \multicolumn{2}{|l|}{$54.007 * * *$} & \multicolumn{2}{|l|}{$16.773 * * *$} & \multicolumn{2}{|l|}{$14.854 * * *$} \\
\hline Adjusted R $^{2}$ & \multicolumn{2}{|l|}{$.28 * * *$} & \multicolumn{2}{|l|}{$.32 *$} & \multicolumn{2}{|l|}{$.42 * * *$} \\
\hline
\end{tabular}

$* p<0.05, * * p<0.01, * * * p<0.001$. 
294

295

296

297

298

299

300

301

302

303

304

305

306

307

308

309

310

311

312

313

314

315

316

317

318

319

320

\section{Discussion}

This novel study investigated intention to cook from basic ingredients using different modes of instruction. The impact of enjoyment, confidence and perceived difficulty of the task on intention to cook from basic ingredients was also examined. It is the first study in this area to design experimental conditions based on BCTs.

Overall, while the intervention increased participants' intentions to cook the meal again from basic ingredients, no differences were found between the different conditions. The conditions in this study were designed with accumulating BCTs. This was deliberate, as it was important that if there was an optimal instruction mode for learning the dish, it was necessary that the instruction mode was relevant and applicable to the general population, and therefore it was necessary that each condition had ecological validity. The modes for learning to cook that were used as conditions had naturally accumulative BCTs and therefore, it was decided to implement the study with an accumulative design instead of manipulating the conditions and losing ecological validity and relevance. The results show that adding video (in whichever format full, segmented, or full control over video) to basic written instructions (a recipe) provides no additional benefit above and beyond providing instruction when participants get the experience of practically preparing the dish. These results imply that what is important for increased intention to make the meal in the future was the practical experience of making the dish. However, as our sample size was smaller than the number required, due to nonattendance, the non-significant result between conditions may be due to the study being under powered. Therefore the research needs to be repeated with a larger sample before any conclusions can be reached. In addition, in a setting where practical experience is not possible, these different modes of instruction (and the accumulating BCTs) may provide additional benefit or may have differences on intention to cook from scratch. This was not investigated in this study and could be key for interventions that aim for widespread dissemination, such as through the internet. Adam et al. [32] reported that from an online cooking intervention, there was a significant increase in the numbers cooking from fresh ingredients. However, differences between mode of instruction was not considered in this study. Short video clips were provided throughout the intervention and participants 
321

322

323

324

325

326

327

328

329

330

331

332

333

334

335

336

337

338

339

340

341

342

343

344

345

346

also had the opportunity to submit photographs after they tried a recipe, differences between those who submitted evidence of their practical experience of trying the recipes and those that did not, were not reported. In addition, smaller video clips of the more advanced or complicated skills in a recipe were not available for those that did not want to watch the video clip in its entirety. These components should be considered in future online cooking interventions, to assess differences between BCT's when practical experience is not an integral component of the intervention.

The explanation of theory used in the design of cooking interventions has been lacking [15]. In this study, theory clearly informed the design. The results, the significance of confidence and enjoyment as predictors, indicate that self-efficacy theory [26] and self-determination theory [27] may have the potential to strongly underpin interventions to increase cooking from basic ingredients with positive outcomes. Given the lack of theory-based studies, it is difficult to make comparisons between interventions and how different techniques are implemented and this study provides initial evidence of theoretically underpinned research having positive outcomes in cooking from basic ingredients. Our results show that for intention to cook again, with practical experience the only BCT required is the provision of information. Without clearly identifying BCTs it is difficult for comparisons on the important BCTs for other elements for cooking. With greater theoretical explanations in the cooking area, there would be greater comparisons which would enable improvements in intervention design. In addition, using the BCT taxonomy would allow greater ease of incorporating successful BCTs identified in other behaviour change interventions such as increasing physical activity.

The positive correlations between confidence, enjoyment and likelihood to cook again and the negative correlation with perceived difficulty, highlight how these elements are linked. These elements should be considered when designing future cooking and food skills interventions. The increase in confidence after practical experience of cooking seen here is similar to findings by Wriden et al. [46]. Furthermore, the results support previous qualitative research which noted that those participants with a higher cooking efficacy attributed this to practical "hands on" cooking experiences they had at a younger age [23]. Thus, it appears that practical cooking experience increases cooking 
confidence and should be an essential component of interventions or programmes with the aim of increasing home meal preparation and cooking from scratch.

The observed decrease in perceived difficulty over the course of the experiment is regarded as a positive outcome of this intervention. This mirrors findings by Chapman-Novakofski and Karduck [31]. The desire for meals that require no effort has been previously inferred as a reason for not cooking from basic ingredients [23]. Addressing this by reducing the perceived difficulty may encourage general consumers to cook from basic ingredients.

The role of enjoyment in cooking is not the focus of studies and interventions that promote cooking skills with a health agenda [40]. However, this research indicates that enjoyment may be a crucial component to the success of cooking interventions. Our results show that enjoyment increased with practical cooking experience and enjoyment was the most significant predictor of intention to cook from basic ingredients in the future. Previous studies have also found enjoyment to be the most significant predictor of cooking skills [25] and that adults who enjoyed cooking were most likely to have engaged in meal preparation at younger ages [47]. Health promoting cooking interventions should have a strong emphasis on the enjoyment and fun in cooking for optimal outcomes.

The final regression model (model 3) accounted for a substantial amount of the variance (42\%) in likelihood to cook again from basic ingredients, with $32 \%$ of the variance attributed to baseline variables. This highlights that interventions may have limited impact if initial favourable conditions are not present. The additional $10 \%$ of variance in the regression model 3 suggests the practical experiment contributed significantly to their intention to cook from basic ingredients. This appears to support past qualitative research which suggests that practical experience increased self-efficacy in cooking and this facilitated cooking from basic ingredients [23, 49]. Both enjoyment and confidence remained significant predictors in the final model, highlighting the importance of these factors when considering the design and implementation of cooking interventions. However, it should be noted that a lack of confidence at the beginning of the intervention also had a significant impact on intention to cook again. As Beta for confidence at start was negative in Model 2 this may indicate that effects were higher for people who lacked most confidence at start of the study. The unaccounted variance 
374

375

376

377

378

379

380

381

382

383

384

385

386

387

388

389

390

391

392

393

394

395

396

397

398

399

400

$(58 \%)$ in intention to cook from basic ingredients again, may be attributable to external factors which were not controlled in this experiment. In the home environment previously explored barriers to cooking from basic ingredients include family preferences, financial restraints, time pressures of work and family commitments and previous negative experiences [23]. Future interventions should take these external factors into consideration and design strategies that help participants cope with and overcome these barriers to maximise the likelihood of cooking from basic ingredients again in the home environment. Methods to overcome some of these barriers may include: 1) including children in the cooking process, as greater exposure to different foods has been shown to increase willingness to try foods [50]; 2) calculating monthly food budgets for using basic ingredients, where the initial cost is greater for investment in certain ingredients but over the month the cost works out the same as, if not cheaper than, convenience products, and helping participants to calculate their own budgets; and 3) highlighting quick, easy and tasty recipes.

\section{Implications for cooking interventions}

Our findings highlight the key elements of cooking interventions to be enjoyment, practical experience and confidence. Recently, in a Belgian population it was shown that only $30 \%$ of household food budgets are spent on raw or basic ingredients [13]. Similarly, in this study, only $28 \%$ of participants had not used convenience products in previous attempts at preparing a Lasagne. The negative health aspects of processed and convenience products $[21,22,51]$ have been noted and it has also been shown that health is a principal motivator for cooking from basic ingredients [23].

Therefore, it is important for health-promoting cooking interventions to support cooking from basic ingredients. From our results it can also be seen that increasing confidence and practical experience are essential to improving intentions to cook from basic ingredients and strategies should be implemented to improve confidence in cooking. Interventions should include some level of practical cooking experience, ideally some element in each session if feasible. As there were no additional benefits to providing extra modes of instructions (accumulating BCTs), our results show that for cooking interventions that can include practical elements need only provide instructions (a recipe) and let their participants practice. This would help reduce the cost of interventions, with the removal of 
401

402

403

404

405

406

407

408

409

410

411

412

413

414

415

416

417

418

419

420

421

422

423

424

425

426

427

costs associated with hiring a demonstrator or purchasing technology for displaying videos, and in turn make the interventions more sustainable, economical and enticing to government and health promotion bodies as potential health-promoting programmes. A main finding from our study is the importance of enjoyment in cooking which may not always be an element considered in cooking interventions that are focused on health [40]. Interventions should be practical with some fun activities (to increase enjoyment of cooking) such as introducing food design (plate layout, structure of the food, creating sculptures out of food) or competitions (best outcome, best effort/improvement, participants voted favourite) or games such as participants pick ingredients for each other or suggest ingredients that should be the focus of the next session. In addition, they could include achievable cooking activities to increase confidence, this could be implemented by starting with very basic simple tasks, however, a demonstration of the final more complicated dish is given during the first session as a target for the participants to work towards and after completion of the final session, a demonstration of the initial simple task could be given. A key element to this would be that an appropriate and achievable task is planned in a progressive manner. The final session would highlight to the participants how far they have progressed and emphasise the new skills they have learned.

\section{Strengths, Limitations and Future Research}

Key strengths of this study are its randomised control design and ecological validity of each condition which incorporated and explicitly highlighted the use of some BCTs commonly implemented in cooking research. Some limitations to this study must be considered and in turn provide areas for improvement for future research.

Although participants recruited were screened regarding their use of mainly prepared ingredients, a small number of this sample had previously made a lasagne from basic ingredients. The recipe was chosen and adapted from the funding body's cookbook. Future interventions should consider using a relatively new or unknown recipe not commonly cooked in its target population. The sample consisted of young mothers only and this could be regarded as a further limitation of this study. Currently, mothers remain the main cook in households [39], and perhaps targeting a different sample of the population, such as young men or students would yield different results that can be compared. 
428

429

430

431

432

433

434

435

436

437

438

439

440

441

442

443

444

445

446

447

448

449

450

451

452

Furthermore, the results should be considered within the cultural context of the populations of the UK and Ireland; replicating the study in other populations would allow for an understanding of key cultural differences in learning. In addition, differences in time to completion of the cooking experiment may have an influence and future research could implement time restrictions for completion or control for time differences in analysis. Time was not strictly controlled in the current study as it was felt to be essential that all participants experienced the whole cooking process to completion of the dish, by limiting time some participants would not finish and this may act as a future deterrent to repeating the process.

Although the use of a randomised controlled design was a strength of the study, it would be interesting to repeat this study and allocate participants to their preferred cooking instruction method and assessing the impact of this on learning. As there were no differences between the conditions on the various measures, by allowing participants choose their method, this would increase autonomy, a key aspect of adult learning [52]. In addition, as there are different types of learners, allowing participants the choice of method that is closest to their learning style may achieve better outcomes and would establish initial evidence in how different learning styles impact cooking education [53].

Focus group discussions were conducted with the participants after each experimental session and after the participants tasted their lasagnes. These were designed to gather insights and experiences of the cooking experiment and cooking in general and included topics on: overall impressions of the lasagne; transferability of skills; adapting the recipe for health and family preferences; barriers to cooking; sources of learning; and engagement with, liking, use of, and effectiveness of technology. Focus group discussions were chosen as this elicits a rich, detailed descriptive understanding of the experience that would enable future adaptation and improvement. Future research could implement these focus group findings (to be published) as a questionnaire to quantitatively measure postexperiment experiences of the cooking task which would provide further control variables for analysis.

\section{Conclusions}


454 Enjoyment and confidence in cooking a meal have a significant impact on intention to cook from

455 basic ingredients. However, providing additional information in different modes over and above a

456 recipe and practical experience was not found to offer added benefits on intention to cook from basic

457 ingredients. In light of our results cooking and food skills interventions should focus on the practical

458 experience of cooking that is enjoyable, to increase confidence, with the aim of improving the

459 likelihood of increasing and maintaining cooking from basic ingredients within the home.

460

461 Competing Interests

462 The authors declare that there are no conflicts of interest.

464 Funding

465 This material is based upon work supported by safefood, The Food Safety Promotion Board, under 466 Grant No. 11/2013 for the period May 2014 - October 2015.

\section{Author Contributions}

469 All authors were involved in the design of the study. FL, DS, LH, AMC, EM and LM were

470 involved in the running of the sessions and observing the participants during the experiment.

471 FL and MD conceived the manuscript. FL conducted the data analysis with advice from MD.

472 FL drafted the manuscript and MD edited. All authors read, edited and approved the final

473 manuscript. 
476

477

478

479

480

481

482

483

484

485

486

487

488

489

490

491

492

493

494

495

496

497

498

499

500

501

The authors would like to acknowledge the participants and safefood for feedback and input into this study.

\section{References}

1) Ogden CL, Carroll MD, Kit BK, Flegal KM. Prevalence of childhood and adult obesity in the United States, 2011-2012. Jama. 2014;311(8):806-14.

2) Olshansky SJ, Passaro DJ, Hershow RC, Layden J, Carnes BA, Brody J, Hayflick L, Butler RN, Allison DB, Ludwig DS. A potential decline in life expectancy in the United States in the 21st century. N Engl J Med. 2005;352(11):1138-45.

3) Lim SS, Vos T, Flaxman AD, Danaei G, Shibuya K, Adair-Rohani H, AlMazroa MA, Amann M, Anderson HR, Andrews KG, Aryee M. A comparative risk assessment of burden of disease and injury attributable to 67 risk factors and risk factor clusters in 21 regions, 19902010: a systematic analysis for the Global Burden of Disease Study 2010. Lancet. 2013;380(9859):2224-60.

4) Drewnowski A, Fiddler EC, Dauchet L, Galan P, Hercberg S. Diet quality measures and cardiovascular risk factors in France: applying the Healthy Eating Index to the SU. VI. MAX study. J Am Coll Nutr. 2009;28(1):22-9.

5) Eyre H, Kahn R, Robertson RM, Clark NG, Doyle C, Gansler T, Glynn T, Hong Y, Smith RA, Taubert K, Thun MJ. Preventing cancer, cardiovascular disease, and diabetes: a common agenda for the American Cancer Society, the American Diabetes Association, and the American Heart Association. CA Cancer J Clin. 2004;54(4):190-207.

6) Zizza CA, Xu B. Snacking is associated with overall diet quality among adults. J Acad Nutr Diet. 2012;112(2):291-6.

7) Moore LV, Roux AV, Nettleton JA, Jacobs DR, Franco M. Fast-food consumption, diet quality, and neighborhood exposure to fast food the multi-ethnic study of atherosclerosis. Am J Epidemiol. 2009; doi: 10.1093/aje/kwp090. 
8) Monteiro CA, Levy RB, Claro RM, de Castro IRR, Cannon G. Increasing consumption of ultra-processed foods and likely impact on human health: evidence from Brazil. Public Health Nutr. 2011;14(01):5-13.

9) Wolfson JA, Bleich SN. Is cooking at home associated with better diet quality or weight-loss intention? Public Health Nutr. 2015;18(08):1397-406.

10) Beck ME. Dinner preparation in the modern United States. Brit Food J. 2007;109(7):531-47.

11) Worsley T, Wang WC, Wijeratne P, Ismail S, Ridley S. Who cooks from scratch and how do they prepare food? Brit Food J. 2015;117(2):664-76.

12) Steenhuis IH, Vermeer WM. Portion size: review and framework for interventions. Int J Behav Nutr Phys Act. 2009;6(1):1.

13) Daniels S, Glorieux I. Convenience, food and family lives. A socio-typological study of household food expenditures in 21st-century Belgium. Appetite. 2015;94:54-61.

14) Reicks M, Trofholz AC, Stang JS, Laska MN. Impact of cooking and home food preparation interventions among adults: outcomes and implications for future programs. J Nutr Educ Behav. 2014;46(4):259-76.

15) McGowan L, Caraher M, Raats M, Lavelle F, Hollywood L, McDowell D, Spence M, McCloat A, Mooney E, Dean M. Domestic Cooking and Food Skills: A Review. Crit Rev Food Sci Nutr. (just-accepted) 2015:00-00.

16) Jones M, Dailami N, Weitkamp E, Salmon D, Kimberlee R, Morley A, Orme J. Food sustainability education as a route to healthier eating: evaluation of a multi-component school programme in English primary schools. Health Educ Res. 2012;27(3):448-58.

17) Caraher M, Seeley A, Wu M, Lloyd S. When chefs adopt a school? An evaluation of a cooking intervention in English primary schools. Appetite. 2013;62:50-9.

18) Jamie Oliver Food Foundation: Our Mission. http://www.jamieoliverfoodfoundation.org.uk (2015). Accessed 16.07.15.

19) U.S. Department of Health and Human Services, National Institutes of health, National Cancer Institute. Down Home Healthy Cooking. 2016. http://www.cancer.gov/aboutcancer/causes-prevention/risk/diet/down-home-healthy-cooking.pdf Accessed 10 Sep 2016. 
20) Chen RCY, Lee MS, Chang YH, Wahlqvist ML. Cooking frequency may enhance survival in Taiwanese elderly. Public Health Nutr. 2012;15(07):1142-9.

21) van der Horst K, Brunner TA, Siegrist M. Ready-meal consumption: associations with weight status and cooking skills. Public Health Nutr. 2011;14(02):239-45.

22) Lerner A, Matthias T. Changes in intestinal tight junction permeability associated with industrial food additives explain the rising incidence of autoimmune disease. Autoimmun Rev. 2015;14(6):479-89.

23) Lavelle F, McGowan L, Spence M, Caraher M, Raats M, Hollywood L, McDowell D, McCloat A, Mooney E, Dean M. Barriers and facilitators to cooking from 'scratch' using basic or raw ingredients: A qualitative interview study. Appetite. 2016 (just accepted).

24) Monteiro CA, Cannon G, Moubarac JC, Martins AP, Martins CA, Garzillo J, Canella DS, Baraldi LG, Barciotte M, da Costa Louzada ML, Levy RB. Dietary guidelines to nourish humanity and the planet in the twenty-first century. A blueprint from Brazil. Public Health Nutr. 2015;18(13):2311-22.

25) Hartmann C, Dohle S, Siegrist M. Importance of cooking skills for balanced food choices. Appetite. 2013;65:125-31.

26) Bandura A. Self-efficacy: toward a unifying theory of behavioral change. Psychological review. 1977;84(2):191.

27) Deci EL, Ryan RM. Self-determination theory: A macrotheory of human motivation, development, and health. Canadian psychology/Psychologie canadienne. 2008;49(3):182.

28) Penn L, Moffatt SM, White M. Participants' perspective on maintaining behaviour change: a qualitative study within the European Diabetes Prevention Study. BMC public health. 2008;8(1):235.

29) Stead M, Caraher M, Wrieden W, Longbottom P, Valentine K, Anderson A. Confident, fearful and hopeless cooks: findings from the development of a food-skills initiative. Brit Food J. 2004;106(4):274-87. 
30) Hartman H, Wadsworth DP, Penny S, van Assema P, Page R. Psychosocial determinants of fruit and vegetable consumption among students in a New Zealand university. Results of focus group interviews. Appetite. 2013;65:35-42.

31) Chapman-Novakofski K, Karduck J. Improvement in knowledge, social cognitive theory variables, and movement through stages of change after a community-based diabetes education program. J Am Diet Assoc. 2005;105(10):1613-6.

32) Adam M, Young-Wolff KC, Konar E, Winkleby M. Massive open online nutrition and cooking course for improved eating behaviors and meal composition. Int J Behav Nutr Phys Act. 2015;12(1):1.

33) Graves TB, Collins BC, Schuster JW, Kleinert H. Using video prompting to teach cooking skills to secondary students with moderate disabilities. Educ Train Dev Disabil. 2005:34-46.

34) McGraw-Hunter M, Faw GD, Davis PK. The use of video self-modelling and feedback to teach cooking skills to individuals with traumatic brain injury: a pilot study. Brain Inj. 2006;20(10):1061-8.

35) Taber-Doughty T, Bouck EC, Tom K, Jasper AD, Flanagan SM, Bassette L. Video modeling and prompting: A comparison of two strategies for teaching cooking skills to students with mild intellectual disabilities. Educ Train Autism Dev Disab. 2011;1:499-513.

36) Bloom BS. Taxonomy of educational objectives: The classification of educational goals .1956

37) Anderson LW, Krathwohl DR, Bloom BS. A taxonomy for learning, teaching, and assessing: A revision of Bloom's taxonomy of educational objectives. Allyn \& Bacon; 2001.

38) Michie S, Richardson M, Johnston M, Abraham C, Francis J, Hardeman W, Eccles MP, Cane J, Wood CE. The behavior change technique taxonomy (v1) of 93 hierarchically clustered techniques: building an international consensus for the reporting of behavior change interventions. Ann Behav Med. 2013;46(1):81-95.

39) Lavelle F, Spence M, Hollywood L, McGowan L, Surgenor D, McCloat A, Mooney E, Caraher M, Raats M, Dean M. Learning cooking skills at different ages: a cross-sectional study. Int J Behav Nutr Phys Act. 2016; doi:10.1186/s12966-016-0446-y. 
40) Lang T, Caraher M. Is there a culinary skills transition? Data and debate from the UK about changes in cooking culture. J HEIA. 2001;8(2):2-14.

41) Safefood. North/South Ireland Food Consumption Survey. 2001. Available from: http://www.safefood.eu/SafeFood/media/SafeFoodLibrary/Documents/Publications/Research \%20Reports/NorthSouthIrelandFoodConsumptionSurveyIrishUniversitiesNutritionAllianceS ummaryReport.pdf. Accessed 20 Feb 2017.

42) McGowan L, Pot GK, Stephen AM, Lavelle F, Spence M, Raats M, Hollywood L, McDowell D, McCloat A, Mooney E, Caraher M. The influence of socio-demographic, psychological and knowledge-related variables alongside perceived cooking and food skills abilities in the prediction of diet quality in adults: a nationally representative cross-sectional study. Int $\mathbf{J}$ Behav Nutr Phys Act. 2016;13(1):111.

43) Reed Z, McIlveen-Farley H, Strugnell C. Factors affecting consumer acceptance of chilled ready meals on the island of Ireland. International Journal of Consumer Studies. $2003 ; 27(1): 2-10$.

44) Myers, R.H. Classical and Modern Regression with Applications; 2nd Ed.; PWS-Kent: Boston, 1990

45) Menard, S. (1995). Applied logistic regression analysis. Thousand Oaks, CA: Sage.

46) Wrieden WL, Anderson AS, Longbottom PJ, Valentine K, Stead M, Caraher M, Dowler E. The impact of a community-based food skills intervention on cooking confidence, food preparation methods and dietary choices-an exploratory trial. Public Health Nutr. 2007;10(02):203-211.

47) Laska MN, Larson NI, Neumark-Sztainer D, Story M. Does involvement in food preparation track from adolescence to young adulthood and is it associated with better dietary quality? Findings from a 10-year longitudinal study. Public Health Nutr. 2012;15(07):1150-8.

48) Jabs J, Devine CM. Time scarcity and food choices: an overview. Appetite. 2006;47(2):196204.

49) Wolfson JA, Bleich SN, Smith KC, Frattaroli S. What does cooking mean to you?: Perceptions of cooking and factors related to cooking behavior. Appetite. 2016;97:146-154. 
611

612

613

614

615

616

617

618

619

620

621

622

623

624

625

\section{1}

50) Nicklas, T.A., Baranowski, T., Baranowski, J.C., Cullen, K., Rittenberry, L. and Olvera, N., 2001. Family and child-care provider influences on preschool children's fruit, juice, and vegetable consumption. Nutrition reviews, 59(7), pp.224-235.

51) Moodie R, Stuckler D, Monteiro C, Sheron N, Neal B, Thamarangsi T, Lancet NCD Action Group. Profits and pandemics: prevention of harmful effects of tobacco, alcohol, and ultraprocessed food and drink industries. Lancet. 2013;381(9867):670-9.

52) Taylor DC, Hamdy H. Adult learning theories: Implications for learning and teaching in medical education: AMEE Guide No. 83. Med Teach. 2013;35(11):e1561-72.

53) Pashler H, McDaniel M, Rohrer D, Bjork R. Learning styles concepts and evidence. Psychol Sci Public Interest. 2008;9(3):105-19. 